\title{
CAN WE MAKE THE "NEW URBAN AGENDA" MORE AGE- FRIENDLY FOR ISLAND-BASED OLDER PEOPLE'S HOUSING? A CASE STUDY OF XINZHOU TOWN, CHINA
}

\author{
Qiaowei Yang \\ School of Architecture, Planning, and Landscape, Newcastle University \\ United Kingdom \\ e-mail: q.yang9@ncl.ac.uk
}

\begin{abstract}
The paper uses the "New Urban Agenda" and the "Age-friendly Cities" as research framework, to investigate housing for island-based older people living in one developing area of China. The results identify that local older residents are facing: difficulties in getting modifications and maintenance because of the younger generations' migration and local industrial development, poor affordability of care home living, as well as poor transport links that prevent access to housing services. These issues are caused by the "urban-rural linkages" as well as "urbanization", which are important points in the "New Urban Agenda". Based on the findings, the author argues that future actions need to be done to make the implementation of the "New Urban Agenda" more age-friendly.
\end{abstract}

Keywords : new urban agenda, age-friendly cities, housing, island-based, older people, China

\section{INTRODUCTION}

Cities are viewed as the centre of economic development. In a centrally planned economy before economic reform, the superiority of cities over rural areas in China was reflected in the policy of "Price Scissors", which in short intended to deliver more benefits for cities as well as their residents through trading with rural areas (Imai, 2000; Lin and $\mathrm{Yu}, 2009$ ). Likewise, nowadays, sustainable urbanization is recognized as "a driver of sustainable development"

(https://www.habitat3.org/bitcache/4780d93be4c90a02557afccf6ce9466389a88013? vid=574389\&disposition=inline \&op=view.), which also indicates the strong influence of cities.

In China, due to the unequal policies that prioritised cities' development in the past, the increasing economic and social disparities between urban and rural 
areas has resulted in a series of social issues, for instance, urban-rural income disparity (Tao et al., 2009). Thus, in light of this, the central government has been implementing a set of new policies such as the "Urban-Rural Integration Planning" and the "New Rural Construction" in order to minimise the enlarging gap. In accordance with this, the New Urban Agenda highlights linkages between urban and rural areas as well.

Unfortunately, however, in the interaction with urban area, especially during the process of the country's fast urbanization, rural area seems remain in an inferior position. This has been reflected in the outmigration of population of rural area, which is accelerated by the fast urbanization. China's urbanization rate will reach about 60\% in 2020 (Jian and Huang, 2010), and probably around 75\% in 2050 (Liu, 2011). To date, there are more than 100 million rural migrants living in urban area (NPFPCC, 2010).

In addition, against the background of rapid population ageing across the whole country, rural area is facing another significant demographic change. By the end of 2014 China had about 212 million older people aged 60 and over, which accounted for $15.5 \%$ of the country's total population (NBSC, 2015), and in 2050 there might be about 36.5 per cent of Chinese aged 60 and over (UNDESA, 2015).Therefore, younger generations' migration and rapid population ageing are merging together to shape the landscape of rural area in China significantly, resulting in more ageing issues.

In 2007 WHO (2007) published the framework of Global Age-friendly Cities: A Guide (hereinafter called the Guide), which intended to be helpful for governments to cope with population ageing issues. The Guide builds on WHO's active ageing framework (WHO, 2007), and the so called "age-friendly city" is "an inclusive and accessible urban environment that promotes active ageing" (WHO, 2009 , p.1).Based on the principle that "older people are the ultimate experts in their own lives" (WHO, 2007, p.7), participant local governments conducted bottom-up discussions which involved 1485 older people, 250 caregivers and 515 service providers from 33 cities in 22 counties, including New York in the USA, London in the UK, and Shanghai in China, to name but a few, to initially came together to develop the Guide.

According to the Guide, housing was one of the main concerns of participants, because appropriate housing was essential to the independence and quality of life of older people (WHO, 2007).Nevertheless, in terms of housing's discussion, two gaps in the Guide can be identified. First, the concept of housing discussed is relatively broad, in other words, WHO does not specify the types of housing and elaborate on each of them specifically. Second, housing conditions in Chinese context is not covered in the section of the Guide, which indicates that the framework needs to be put into practice in China for getting specific feedback.

Compared with other counterparts, island housing is a topic that has been overlooked for a long time. However, existing literature on this field, such as case studies conducted by Isik and Tulbentci (2008) and Hadjiyanni (2000) in Cyprus, research carried out in Ireland by McElduff, Peel and Lloyd (2013), an investigation into the case of Key West, Florida by Schively(2008), to name but a few, shows potential research value in this field. 
Generally speaking, however, the understanding of island-based housing is under researched. The literature gap becomes more prominent when it being put in the context of global population ageing. Therefore, drawing on the perspectives of "New Urban Agenda" and "Age-friendly Cities", the present study will focus on Chinese context to investigate the island-based older people's housing conditions, discovering some potential existing issues. The author hopes that the findings of the case study could contribute to the developments of both "New Urban Agenda" and "Age-friendly Cities".

\section{The Study Case}

The city of Anqing lies on the north bank of the mid-lower reaches of the Yangtze River in the southwest of Anhui province (see Figure 1). At the end of 2014, the city of Anqing covered an urban area accounting for $81 \mathrm{~km}^{2}$ and urban residents of 808,000 (SBAP, 2015).

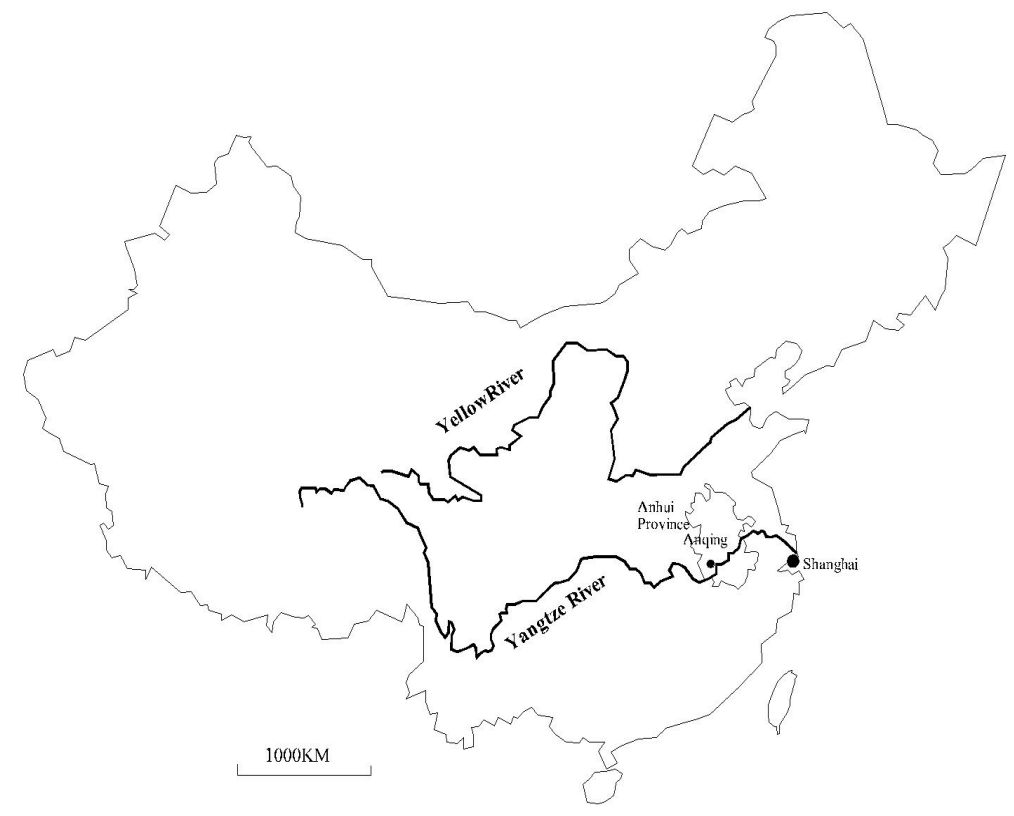

Figure 1. Anqing City in China (Source: the author)

By the end of 2013, the proportion of older people aged 65 and over in Anqing had reached 14.8\% (SBAP, 2014), which was the highest in Anhui Province. In 2016, the population of older people in the urban area has been attained more than 140,000 , showing a significant multi-trends of ageing amongst the very old, emptynesting and disabling(http://xwxx.anqing.gov.cn/DocHtml/1/99/12/00080851.html). 
Xinzhou Town is located on an alluvial delta of the Yangtze River. The town is 15 kilometres southeast to the urban area of Anqing, and it covers an area of $54.21 \mathrm{~km}^{2}$, and has a population of 11200 . The river island looks like a leaf ,encicrled by the river (see Figure 2).

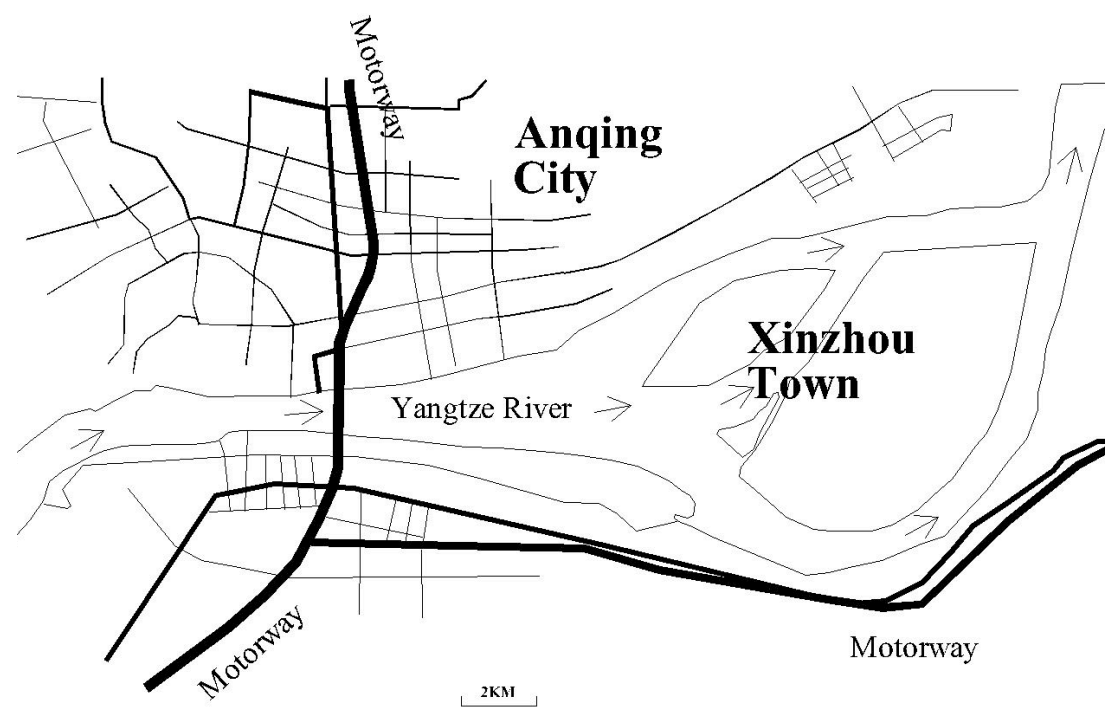

Figure 2. Xinzhou Town (Source: the author)

\section{THEORY / RESEARCH METHODS}

Starting in the 1990s the China's housing reform, which is a representative of the process of economic transition,invites tremendous changes in housing market shifting its form from former work-unit-based housing to commercial residential building. Although changes in neighbourhood forms, housing preference, lifestyle and residential mobility due to housing transformation, post-reform commodity housing estates not only decrease the neighbourly interaction, but also gives rise to the attachment to physical environment (Zhu et al.,2012).

Housing is essential to safety and well-being (WHO, 2007).An ageing population results in a greater proportion of households spending more time at home (House of Lords, 2005). In the meantime, older people become more sensitive to ambient environmental factors, for instance the temperature inside building (Willis et al., 2011), because of changes both in life-style and physical conditions. Therefore, to older people, housing-related well-being is highly sensitive to changes in the physical environmental effects underpinning housing characteristics (CostaFont, 2013; Gilroy, 2005). 
Improvement of well-being has been proved to lead to other benefits as well in many cases (Stoll et al., 2012), for instance, health and longevity (Diener and Chan, 2011).However, there are a number of barriers in the process of achieving older people's well-being in their residential building, which has been identified from previous investigations either in developed area or developing countries (WHO, 2007; Wezemael and Gilroy,2007; Gilroy,2005; Gilroy,2006).Therefore, the housing-related subjective well-being serves as an critical indicator of the agefriendliness of housing for older people.

In short, well-being can be measured by objective measurements and subjective measurements. In objective measurements, well-being can be measured through a series of fixed and definite objectives. Eudaimonists' theories, which are featured by the Self Determination Theory (Ryan and Deci, 2001) and the multidimensional account (Ryff and Singer,1998), propose that well-being should consist in meeting core human needs, and lists of needs are derived from theories of human flourishing that are only partly based on experimental findings (Tiberius,2006). While in subjective measurements, well-being is measured by respondents' self-reports evaluating their life and feelings (Krueger and Stone, 2014).

Furthermore, Layard (2010) highlights the importance of the quantitative study of well-being, because "every survey of individuals should automatically measure their well-being, so that in time we can really say what matters to people and by how much", and "it will produce very different priorities for our society"(Layard,2010,p.535).

\section{Research Methods}

Drawing on the discussion stated above, both qualitative and quantitative methods were employed to collect data. First, based on the 9 items in the housing section of the Guide as well as the measurements of well-being the researcher developed a questionnaire of 9 closed-ended questions.One typical question of the questionnaire was designed as follows: To what extent do you agree that affordable housing is available for you? 1.Strongly agree; 2. Agree; 3. Undecided; 4.Disagree; 5. Strongly disagree. The questionnaire was distributed to local older people. The function of the collected data from it was to discover which aspects of housing had significant negative influence on older people's well-being.

Secondly, based on the findings of the questionnaire the researcher conducted interviews with local people. In each interview, designed semi-structured questions were carried out, aiming to identify why older people valued these issues and what specific aspects concerned them.

Thirdly, the researcher started deskwork after the fieldwork.In the deskwork, the author reviewed exsiting data such as related documents, reports and policy, trying to look for social and economic evidence to interpret the cause of identified issues. 


\section{RESULTS AND DISCUSSION}

\section{Modifications and Maintenance : Younger Generations' Outmigration And Local Industrial Development}

WHO points out in the Guide that familiar surroundings make people feel part of the local community, and for this reason, older people are reluctant to move (WHO, 2007).Likewise, in traditional Chinese culture, people are attracted to their native land and unwilling to leave it (an tu zhong qian).However, local older residents are facing continuous migration of younger generations to large cities for seeking better work opportunities and better urban life.

Being a developing medium-sized city, the general economic condition of Anqing is inferior to its more developed counterparts in the east. Anqing's economic aggregate is relatively low, and so does for the per capita as well (Wang, 2008). For instance, in 2014 the GDP per capita of Anqing was about 28800 RMB Yuan (less than 5000 US Dollars), while the GDP per capita of Hefei, the provincial capital city of Anhui Province, was around 67400 RMB Yuan (more than 10000 US Dollars), and that of Shanghai in the same year was 97300 RMB Yuan (about 15850 US Dollars).

As a consequence, the remarkable gap between Anqing and more developed areas drives a large number of young people to migrate to big cities for pursuing better life. At the inter-province level, the development of floating population in Anhui Province presents the normalization and the long- term trend ( $\mathrm{Yu}$ and Tian, 2015).The majority of migration population of Anhui Province flows to neighbouring Yangtze River Delta Region that includes Jiangsu Province, Zhejiang Province and Shanghai, mainly due to the proximity of distance (Guo, 2012).At the provincial inter-city level, the spatial separation of floating population is reflected in the preference to move to provincial capital city, Hefei, which is a typical second tier city of China and the convergence centre of provincial population (Guo,2010).Moreover, it has been identified that the proportion of young population is increasing and the older counterpart is decreasing in the migration population ( $\mathrm{Yu}$ and Tian, 2015).

(http://www.aqtj.gov.cn/index.php? $\mathrm{m}=$ content $\& \mathrm{c}=$ index $\& \mathrm{a}=$ show \& $\mathrm{catid}=239 \& \mathrm{id}=5$ 81) on the city's population condition shows explicitly that the large population of migration has caused shortage of labour force in the city, and the situation is even worse than that of several neighbouring cities along the bank of Yangtze River in the province. As a result of the large outmigration population, as the report points out that old-age dependency rate of Anqing has risen to $22.6 \%$.

The proportion of the population aged 65 or over in Xinzhou Town was $16.74 \%$ in 2010, which was one of the highest figures in the city of Anqing (http://aqxxgk.anqing.gov.cn/show.php?id=168073). According to the survey of the Statistic Bureau of Anqing, the overwhelming reason for the high proportion of older people in Xinzhou Town is the outmigration of young people.

Modification and maintenance for housing are two critical aspects in housing of an age-friendly city (WHO, 2007).Like many other rural areas in China, the 
dominant housing for local residents is self-built house, usually with two stories. In other words, the work of modification and maintenance for their houses is individual responsibilities. Unfortunately, for empty-nesting older people, it might be more difficult for them to carry out these actions without their younger family members' help.

The local single industrial development of agriculture results in insufficiency in development of housing industry, and as a consequence, there are no professional housing maintenance workers available on the river island. What's more, if their younger family members' financial assistance is unavailable, then the cost for modification or maintenance might be another barrier for older people to enjoy high quality housing. In 2014, per capita annual net income of local peasants was only 11077 RMB Yuan (http://aqxxgk.anqing.gov.cn/show.php?id=376107).

\section{Affordability : Living in Care Home}

Affordability of housing is one of the critical factors that have significant implications for older people's QoL (WHO, 2007).Nevertheless, the Guide discusses the affordability mainly from the case of rented housing or moving, which is different from the context in Chinese rural area. Chinese traditional concepts of filial piety under which children are responsible for the care and support of their parents are widely held (Bartlett and Phillips, 1997), but because of the fast socioeconomic changes as well as demographic shifts ageing in institution is gaining popularity across the whole society (Feng et al., 2011). To a great extent, the rapid development of care homes in China is a reflection of the changing role of family for supporting older people's living, mainly due to the increasing number of smaller families (Wu et al., 2016). Care homes in China can be divided into two types: government-operated and privately-owned. Due to limited governments' budget and public resources the government-operated care homes are unable to provide sufficient services for so many older people. Hence, privately-owned care homes are becoming important supplements to their counterparts that are run by governments. But, nonetheless, from a case study of privately-owned care homes in Wuhan, we can identify existing issues there, such as inferior quality, low rate of return of investment, shortage of human resources and available spaces and lack of regulations (Yang, 2011).In short, the development of providing care for older people in institution is at its early stage in China, and as Liu and Xiao (2012) argue, the leading role of governments in guiding and administrating the market should not be overlooked.

Therefore, the city government has been making progress in the exploration of this field. In 2014 Anqing was selected as one of the first round of pilot cities for reforming services for older people by the central government

(http://www.mca.gov.cn/article/zwgk/fvfg/shflhshsw/201408/20140800691029.shtm 1). This demonstrates that the city has achieved relatively good progress in helping older people. In 2014, the city had built up 87 home-based community service stations for older people, providing older residents with day care, agency, housekeeping, living caring, entertainment, spiritual comforting. At the same time, 
these service stations integrated health resources, relying on community medical facilities to offer medical rehabilitation service. Communities with better conditions had even built up rooms for daytime caring as well as activities (http://ah.anhuinews.com/system/2014/08/11/006511008.shtml). In 2016, the city government succeeded in applying for a loan of 32 million US Dollars from the World Bank for supporting the construction of the system of urban services for older people including the project of community home-based care service stations for the aged (http://xwxx.anqing.gov.cn/DocHtml/1/99/12/00080851.html).

Currently, the town has only one care home for older people. The care home is able to offer about 110 beds at the moment. But the town government is planning to take advantage of the local excellent ecological environment as well as unique view of landscape to build a care centre for more than 2620 older people's long-term living during the period of the 13th Five -Year Plan, with an investment of 256 million RMB Yuan (http://aqxxgk.anqing.gov.cn/show.php?id=397453).

The construction of the care centre intends not only to meet local needs, but also to attract more older people in the urban area, aiming to alleviate the increasing pressure caused by growing needs for institutional care for older people (http://aqxxgk.anqing.gov.cn/show.php?id=397453). In the 13th Five-Year Plan of Xinzhou Town, its objective is to become the city's "back garden" through the development of sightseeing agriculture (http://aqxxgk.anqing.gov.cn/show.php?id=397453).

Consequently, it can be anticipated that the preference of urban older people of the city for living in Xinzhou because of proximity and good environment. However, the large and intensive investment is expected to cause a rise of care fees in the future. In terms of the fees, a newly built care home based in urban area might offer reference. This urban-area-based care home is named "Yiren Tang", and the fees for services it provides for older care-receiver range from 2166 to 3366 RMB Yuan for per person per month (http://www.yirentangyanglao.com/rzzn/).

Compared with local residents' income (11077 RMB Yuan per capita in 2014), obviously, the services fees of "Yiren Tang" might be quite high. The author argues that before the start of the construction, it is needed to take into account the local older residents' capability of adapting themselves to the increase of fees. What is more, a clear policy for the future plan for the existing facilities as well as older care receivers who are now living there should be mapped in advance, in particular, older people might be concerned about the potential fluctuation of care fees. Unfortunately, the town government does not articulate these aspects in any documents including the Master Plan and the Five-Year's Plan.

\section{Access to Services : Public Transport}

For older people who chose to age in place, the access to services is "particularly important" (WHO, 2007, p33).In order to improve internal public transport facilities, the government has started the construction of island-looping road, which will adjunct existing roads, making each village on the island connected with the others 
(http://www.aqnews.com.cn/html/anqingxinwen/shehuixinwen/201504/188079_201 50416_1.html).

$\bar{B}$ ut, at the moment, the agricultural town is unable to provide rich services for the older residents. Due to the plan of industrial development, modern service industry is not the focus of the future. But, nonetheless, if the local government is seeking to attract urban tourists or even urban older people who are willing to live in the town, one of its top priorities is to address the provision of services.

Existing resources of services within the town that are available to local residents are relatively insufficient. For example, more than 10,000 residents living in the town are sharing the only one community health centre that was set up in 2011 . The community health centre has 10 medical staffs including 7 doctors, 2 registered nurses and 1 pharmacist, as well as 10 observation beds

(http://www.aqnews.com.cn/html/anqingxinwen/shehuixinwen/201504/188079_201 50416_1.html). Apparently, the limited resource of local medical service can not guarantee high QoL for older residents, especially in emergency cases.

Fortunately, residents of the town might be able to share high quality modern services with urban counterparts because of the proximity (the town is only 15 kilometres distant from the downtown area of the city). What is more, according to the master plan for the city, Xinzhou Town is in the service range of downtown area's public facilities, such as advanced hospitals, large shopping centres, to name but a few.

However, up till now, there is no public bus service available for connecting the island town and the urban area on the north bank. The only external transportation option for local residents is ferry. Needless to say that the current traffic conditions hinder the development of economy as well as housing services for older people. According to the plan for public transit of the city, it is anticipated that the island town will not be integrated into the urban public transit network completely until 2030.

Ma et al. (2012) contend that the total transportation demand will be very likely to continue to experience rapid growth in China before 2030. Drawing on this projection, it can be identified that the conflict between local older people's increasing demands of housing services and the backward public transit of the town is becoming more and more prominent.

\section{CONCLUSIONS}

In the context of developing area of China, island-based older people are facing a series of challenges in their housing. Using the WHO's framework of "Age-friendly Cities", the present research can identify these challenges, which comprise difficulties in getting modifications and maintenance because of the younger generations' outmigration and single local industrial development, poor affordability of living in local care home, as well as the barrier to the access to housing services due to the poor public transport links. 
"Urban-rural linkages" as well as "urbanization" are important points in the "New Urban Agenda". However, by introducing the framework of "Age-friendly Cities" into the case study of a river island of Anqing, China, the findings indicate that these elements are not always playing positive roles in delivering high QoL for older people who are living on the isolated island. In this study, older people living on the river island of China are experiencing some difficulties. Based on the findings, the author argues that the implementation of the "New Urban Agenda" needs to take into account specific needs of special groups in particular areas, in particular, future actions need be done to make the "New Urban Agenda" become more age-friendly.

The limitation of the research rests on the selection of case. As stated before, the regional disparity in China is very evident, but this study only focuses on a case in one developing area of China, thus, for other regions, especially more developed parts in the country, new different findings can be expected through more case studies.

\section{ACKNOWLEDGEMENT}

The author would like to thank Prof. Rose Gilroy at Newcastle University in the UK., for her constructive comments on this paper.

\section{REFERENCES}

Bartlett, H. and Phillips, D.R.(1997), Ageing and aged care in the People's Republic of China: national and local issues and perspectives. Health \& Place, 3(3):149-159.

Costa-Font,J.(2013), Housing-related well-being in older people: the impact of environmental and financial influences. Urban Studies, 50(4):657-673.

Diener, E. and Chan, M.Y. (2011). Happy people live longer: subjective well-being contributes to health and longevity. Applied Psychology: Health and WellBeing, 3(1):1-43.

Feng, Z., Zhan, H.J., Feng, X., Liu, C., Sun, M. and Mor, V. (2011), An industry in the making: The emergence of institutional elder care in urban China, Journal of the American Geriatrics Society, 59(4):738-744.

Gilroy, R. (2005), The role of housing space in determining freedom and flourishing in older people. Social Indicators Research, 74:141-158.

Gilroy, R.(2006), Taking a capabilities approach to evaluating supportive environments for older people. Applied Research in Quality Life, 1:343-356.

Guo, Y. (2010), A Study of Spatial Separation of Floating Population in Anhui Province. Journal of Anqing Teachers College (Social Science Edition), 29(10):7-12.(in Chinese)

Guo, Y. (2012), Spatial selection on population flowing out of Anhui Province. Northwest Population,33(3):99-109.(in Chinese)

Hadjiyanni, T.(2000) Children and their housing: insights from the island of Cyprus. Housing and Society, 27(2):19-30. 
House of Lords (2005), Ageing: Scientific Aspects .London: HM Government.

Imai, H. (2000), The labor income tax equivalent of price scissors in prereform China. Journal of Comparative Economics, 28(3):524-544.

Isik, B and Tulbentci, T. (2008), Sustainable housing in island conditions using Alker-gypsum-stabilized earth: a case study from northern Cyprus. Building and Environment, 43:1426-1432.

Jian, X. and Huang, K. (2010), Empirical analysis and forecast of the level and speed of urbanization in China. Economic Research Journal, 45(3):28-39.(in Chinese)

Krueger, A.B. and Stone, A.A. (2014), Progress in measuring subjective well-being. Science, 346:42-43.

Layard, R. (2010), Measuring subjective well-being. Science, 327:534-535.

Lin, J.Y. and Yu, M. (2009), The Political Economy of Price Scissors in China: Theoretical Model and Empirical Evidence. Economic Research Journal, (1):42-56.(in Chinese)

Liu, Y. (2011), Development course, difficulties and trends of Chinese urbanization. Research on Economics and Management, 2011(03):20-26.

Liu, B. and Xiao, R. (2012), Market or system: the case study of business situation and difficulties about socialized institutions for elderly. Population \& Economics, (1):22-29.(in Chinese)

Ma, L., Liang, J., Gao, D., Sun, J. and Li, Z. (2012), The future demand of transportation in China: 2030 scenario based on a hybrid model. Procedia Social and Behavioral Sciences, 54:428-437.

McElduff, L., Peel, D. and Lloyd, M.G. (2013), Informing a framework for coastal planning on the island of Ireland. Town Planning Review,84(4):419-440.

National Population and Family Planning Commission of China (NPFPCC) (2010) To Guide Migration Orderly and Promote Healthy Urbanization: Summary of International Symposium on Migration and Urbanization. Population Research, 34 (5):88-92.

Ryan, R.M. and Deci, E.L. (2001), On happiness and human potentials: A review of research on hedonic and eudaimonic well-being. Annual Review of Psychology, 52:141-166.

Ryff, C. D., \& Singer, B. H. (1998), The contours of positive human health. Psychological Inquiry, 9:1-28.

Schively, C. (2008), Sustainable development as a policy guide: an application to affordable housing in island communities. Environment, Development and Sustainability, 10:769-786.

Statistics Bureau of Anhui Province (SBAP) (2014), Statistical Communiqué of Anhui Province on the 2013 Population of Permanent Residents. Hefei: Statistics Bureau of Anhui Province.

Statistics Bureau of Anhui Province (SBAP) (2015), Statistical Communiqué of Anhui Province on the 2014 Population of Permanent Residents. Hefei: Statistics Bureau of Anhui Province.

Stoll, L., Michaelson, J. and Seaford, C. (2012), Well-being evidence for policy: A review. London: New Economics Foundation. 
Tao, R., Yang, K. and Liu, M. (2009), State capacity, local fiscal autonomy, and urban--rural income disparity in China. China Information, 23(3):355-381.

Tiberius, V. (2006) Well-being: psychological research for philosophers. Philosophy Compass, 1(5):493-505.

National Bureau of Statistics of China (NBSC) (2015), Statistical Communiqué of the People's Republic of China on the 2014 National Economic and Social Development.Source:http:/www.stats.gov.cn/english/PressRelease/201502/t2 0150228 687439.html.

UNDESA. (2015), The 2015 Revision of World Population Prospects. New York: United Nations.

Wang, S. (2008), Developing industry clusters: the only way to revive Anqing's regional economy. Journal of Anqing Teachers College (Social Science Edition), 27(10):1-5.(in Chinese)

Wezemael, J.E.V. and Gilroy, R. (2007), The significance of demographic change in the Swiss approach to private rented housing: a potential for ageing in place? Housing Studies, 22(4):597-614.

Willis, K., Scarpa, R.,Gilroy, R., Hamza, N.(2011), Renewable energy adoption in an ageing population: heterogeneity in preferences for micro-generation technology adoption. Energy Policy, 39: 6021-6029.

Wu, P., Zhou, H. and Zhao, Y. (2016), Research on socialized pension system and its enlightenment: an empirical study in Germany. Journal of Liaoning University (Philosophy and Social Sciences ), 44(2):90-96.(in Chinese)

WHO (2007), Global Age-friendly Cities: A Guide. Geneva: Wold Health Organization.

WHO. (2009), WHO Global Network of Age-friendly Cities. Geneva: World Health Organization.

Yang, L. (2011), The survey of development condition of private nursing home in Wuhan and the suggestion. Social Security Studies, 2011(3):24-30.(in Chinese)

Yu,P. and Tian, F.(2015), Analysis on the floating time expectancy of Anhui population. Journal of Nanjing College for Population Programme Management, 31(3):52-58.(in Chinese)

Zhu, Y., Breiung, W. and Li, S. (2012), The changing meaning of neighbourhood attachment in Chinese commodity housing estates: evidence from Guangzhou. Urban Studies,49(11):2439-2457. 